\title{
SHAPLEY'S ERA
}

\author{
Helen Sawyer Hogg \\ David Dunlap Observatory \\ University of Toronto
}

I am greatly pleased to have a chance to speak at this Symposium about Harlow Shapley, the man who was probably responsible, more than any other, for the shape my life has taken.

In my talk this morning $I$ am repeating a few of the remarks $I$ made at the Centennial Celebration for the birthday of Harlow Shapley last October 17 at the Harvard College Observatory. Some of the people here today were present then, and I trust they will excuse the repetition. But my talk today has a different slant.

First I wish to sketch my personal background, and how I happened to arrive at the Harvard College Observatory in September, 1926. I was born in the nearby city of Lowell which at that time, 1905, had a mile of textile and leather mills stretching along the banks of the Merrimack river. I attended Mount Holyoke College in South Hadley, Massachusetts, in the Connecticut valley. In my junior year, under the influence of a remarkable teacher, Miss Anne Young, I switched a major in chemistry to one in astronomy. Professor Young was the niece of Prof. Charles Young of Princeton, author of the finest astronomy textbooks of the first quarter of this century, books still very useful for their factual information. For the total solar eclipse of January 24, 1925 Miss Young was able to get a special train to take all the college people to a golf links in Connecticut, inside the path of totality. There the glory of the spectacle seems to have tied me to astronomy for life, despite my horribly cold feet as we stood almost knee deep in snow.

A year later, when my graduation was only a few months away, the renowned Miss Annie J. Cannon of Harvard paid a visit to Mount Holyoke. (Figure 1). I still have the diary I kept in the 1920's, up to mid-1927 when apparently life became too complicated for me to keep up with a diary any longer. I read for 1926 Jan. 8 "Miss Young asked me to luncheon with Miss Cannon". For Jan. 11, "Miss Young asked me to introduce people to Miss Cannon Friday". For Jan. 16, "Lunch at Gateway with Miss Cannon. Good prospects for Harvard job". Jan. 22. "Miss 
Young wrote Dr. Shapley a long 1etter". Feb. 2. "Letter from Dr. Shapley saying my chances pretty good". Feb. 24. "Letter from Dr. Shapley offering me Edward C. Pickering Fellowship at Harvard for next year $(\$ 600)$. I am so excited it's hard to put my mind to work!" Feb. 28 "Wrote Dr. Shapley accepting job." And on April 3 I went to Cambridge and saw Dr. Shapley "a nerve-wracking day".

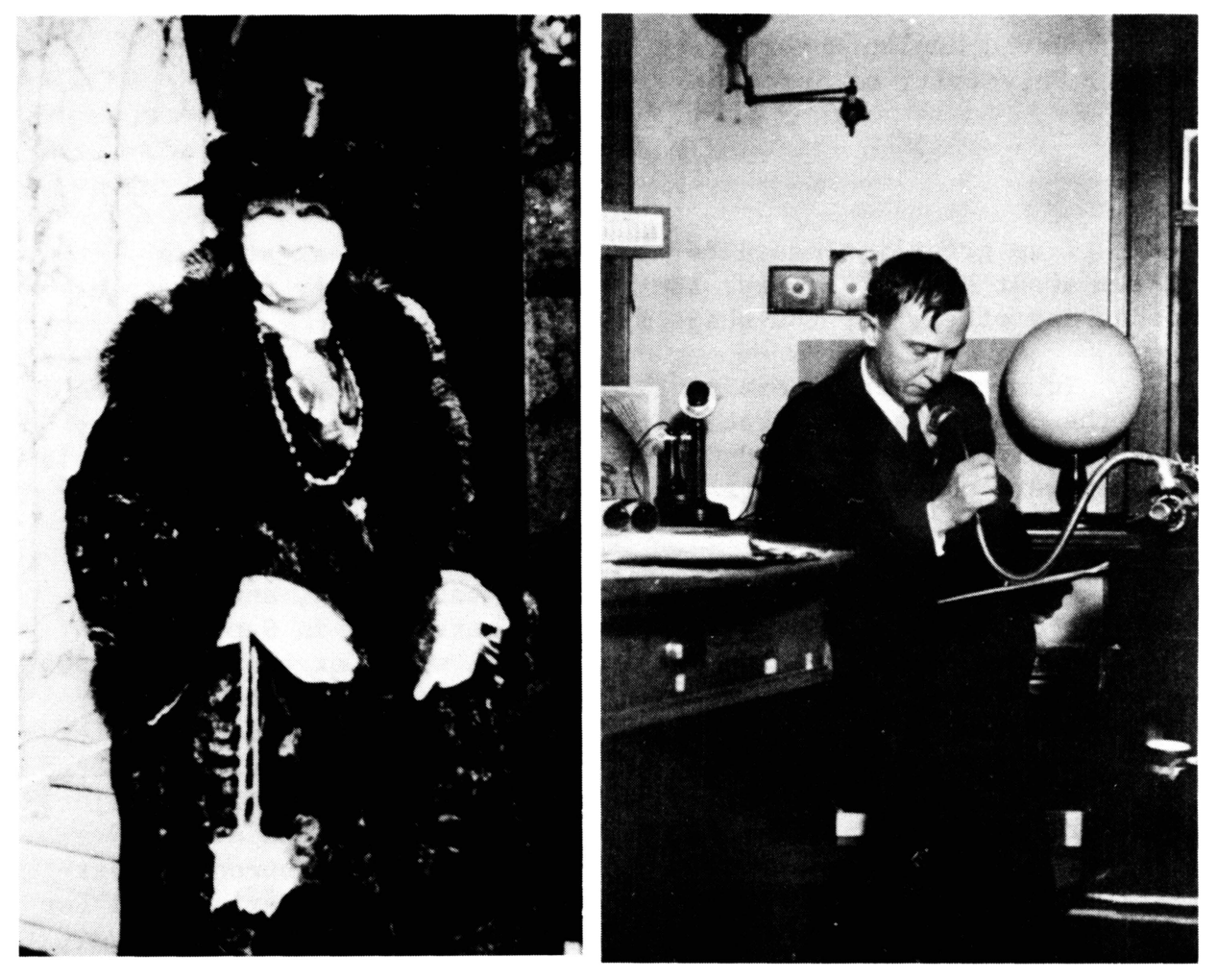

Fig. 1 Miss Annie J. Cannon at Mount Holyoke College, South Hadley, Massachusetts, in January 1926. Photo by Helen Sawyer.

Fig. 2 Dr. Harlow Shapley dictating at his revolving desk in the spring of 1929. Photo by Frank Hogg. 
On Wednesday, September 29 I appeared at the Observatory at 9 a.m. for work and had a long talk with Dr. Shapley. (Figure 2). "I am to help him on a book on star clusters." At Mount Holyoke I had developed a particular fondness for globular star clusters as my favorite celestial objects. It was almost too good to be true that now I was to work on them with the world's authority.

In the 1920 's the Harvard Observatory was a veritable beehive of activity, night and day. Dr. Shapley had been Director for just under five years of his three decades in that post. Edward C. Pickering had died on February 3, 1919 after 42 years as Director, and Solon I. Bailey was in charge of the Observatory for almost three years following his death. In the yard eight or more telescopes were manned by technicians Frank Bowie and Henry Sawyer and some of the graduate students. (Figure 3). Along with those in the southern station they had made a collection of some half a million plates. The buildings had offices for eleven "Members of the Observatory" with positions senior enough to be listed by Solon I. Bailey (1932) in his excellent History and Work of the Harvard College Observatory. William H. Pickering worked at his own observatory in Jamaica, and John S. Paraskevopolous managed the southern station. There were a couple of dozen other workers who fell into two groups - a small group of elderly ladies some of whom, like Miss Florence Cushman, had started work there as early as 1888, and the larger group of newly starting graduate students and young assistants. (Figure 4). This staff was turning out an impressive number of publications which included the Harvard Annals, Circulars, Bulletins, Announcement Cards, Reprints and Reports, with the Monographs series just starting.
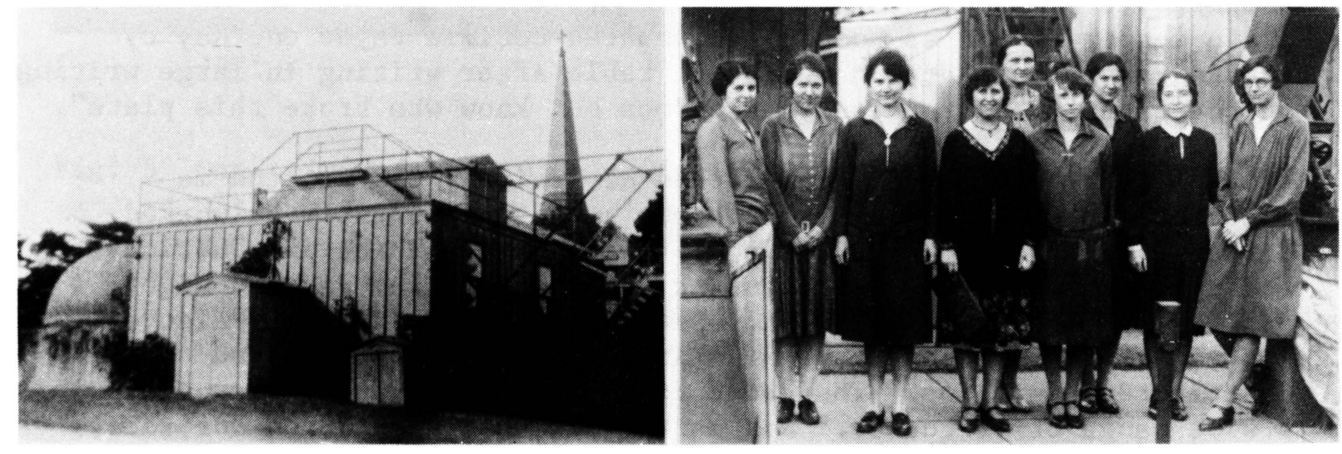

Fig. 3 Harvard College Observatory yard in the 1920's. Photo by Helen Sawyer.

Fig. 4 The young ladies of the Harvard College Observatory, about 1927. Cecilia Payne in rear, Emma T.R. Williams, second from right, Margaret Walton (Mayali) second from left. 
So I became the first person that Dr. Shapley superyised for the doctorate in his own field of star clusters. He had then trained only one student for the doctorate in astronomy, Cecilia Payne, who had received her doctorate from Radcliffe College in 1925 with an outstanding thesis on "Stellar Atmospheres". I worked in an office adjacent to that of Miss Cannon, and day after day I heard her calling out the spectral classifications for the Henry Draper Extension, with the help of her invaluable assistant Margaret Walton Mayall. It was remarkable that Dr. Shapley encouraged me to have my name on so many papers right from my first year there, - a dozen publications, mostly in Harvard Observatory Bulletins, before my doctoral thesis.

In my very first weeks at the observatory, Dr. Shapley instructed me to get out various series of plates to estimate integrated diameters and magnitudes of globular clusters. I soon found that almost exactly one third, 34 of the 103 globular clusters then catalogued in our galaxy could be identified on a single small scale Harvard plate in the Sagittarius-Scorpius region and I marked them in white circles to indicate them, as shown in Figure 5, a slide kindly supplied by Martha Hazen and Barbara Welther from the Harvard collection. I have my first record book in which $\mathrm{Dr}$. Shapley contributed observations as "HS" while $i$ was "HBS". (Display of record book). When I left in $1931 \mathrm{Dr}$. Shapley kindly told me to keep the eyepiece I had been using for five years. I have now been using it for 60 years less one month. (Display of eyepiece). Most of the plate frames around the Observatory then were built for $8 \times 10$ inch plates, which were easy to use. The A series with the Bruce 24-inch refractor, 14 by 17 inches, are much more cumbersome to handle. The plates were considered practically sacred objects in those days. Anyone who had the misfortune to break one was supposed to sign on the plate cover for the misdeed. Miss Hodgdon, the plate keeper (Known as Hodgie) infuriated Cecilia Payne one day by leaving a broken plate on her plate table after writing in large writing on the cover "Miss Payne says she does not know who broke this plate".

Dr. Shapley's usual method of training was to send me instructions on yellow slips of paper, though frequently he worked directly with me, either in his office or mine. These instructions he had dictated with his dictaphone at all hours of the day and night, sitting at his fabulous, round, spinning desk with its many alcoves. His most faithful secretary, Miss Arville D. Walker typed and distributed the slips. They went to all workers at the observatory in a wide range of frequency. Not merely did they keep US on our toes, but they also showed how well up on things $\mathrm{Dr}$. Shapley himself was, especially in his perusal of all the astronomical literature that came into the observatory. I had a fascinating example of this last fall when I was preparing a talk for the Shapley birthday celebration at the Observatory.

I found such a slip dated April 30, 1929 instructing me to make the corrections given in Astronomische Nachrichten 5622 for an earlier article in A.N. 5609. This proved to be a paper by A. Markov 


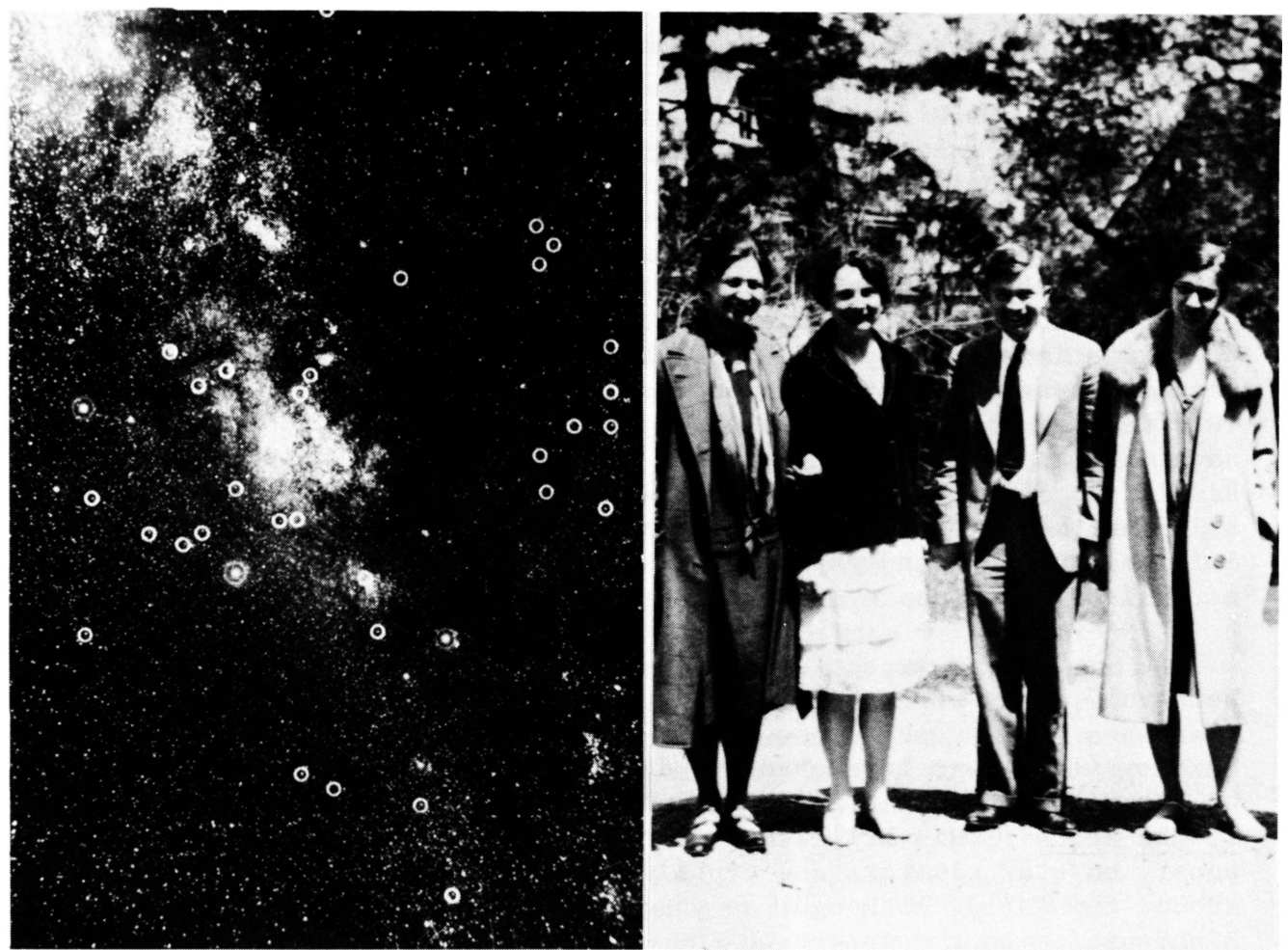

Fig. 5 One third of the 103 globular clusters known in 1930 were marked with white circles by Helen Sawyer on a single Harvard small scale plate of the Sagittarius-Scorpius region.

Fig. 6 Henrietta Swope, Helen Sawyer, Frank Hogg and Adelaide Ames, in the spring of 1929, at Harvard College Observatory.

on "The Nature of Spiral and Gaseous Nebulae". I asked Barbara Welther here to explore the Harvard observatory copy. At first she had a dismal report - the corrections had NOT been made, and I felt inadequate to be a scientist. But after pondering, I realized there were two sets of the Nachrichten here - one at the Observatory, one here in Harvard yard, and further delving by Barbara located the set originally at the Observatory - in which I had carried out Dr. Shapley's instructions. 
It constantly surprises me that I was unaware then of what was actually happening around the observatory, that this was the start of the Harvard-Radcliffe graduate school in astronomy. Master's degrees had been given for some time, mainly for work down at the Yard, I think. But the idea that this was the beginning of an epoch during which, by 1985, according to Owen Gingerich in the November issue of Harvard Magazine, $240 \mathrm{Ph}$.D's would be given in astronomy - that idea certainly never occurred to me. As I have mentioned, Cecilia Payne became the first, receiving the Ph.D. from Radcliffe in 1925, because Harvard did not then give doctorates in science to women, and her thesis "Stellar Atmospheres" became Harvard Monographs No. 1. Frank Scott Hogg, a Canadian with an honours degree from the University of Toronto became a graduate student at the same time as I did, and received the first doctorate in astronomy in 1929 given by Harvard University. (Figure 6). Cecilia Payne was his supervisor, and also trained Emma T.R. Williams (who married Alexander Vyssotsky) and who received her doctorate from Radcliffe in 1930. I received the fourth doctorate in 1931, again from Radcliffe. In retrospect I can see that it was the combination of the brilliant minds of Harlow Shapley and Cecilia Payne, with their originality, zeal and enthusiasm, that provided the stimulus needed to establish the graduate school here.

Another aspect of my association with Shapley that I realized belatedly, only after several decades, is that I worked with him at a time when he was very close to the peak of his scientific career. Shapley (1969) was less than two decades past his journalism career as he described it in his autobiographical memoirs "Through Rugged Ways To The Stars". His brilliant Mount Wilson researches with more than 80 papers on star clusters and cepheids, had had ample time to circulate around the world. Although, as you have just heard from Michael Hoskin, his decision on the nature of the spiral nebulae was in error - an error induced by the proper motions of Adriaan van Maanen - the picture he had drawn of the galaxy surrounded by globular clusters concentrated toward its center, was essentially correct, though improvements would be made to the scale. The controversial decision on the absorption of 1ight in space had not yet been made. The depression had not yet hit, making the perennial seeking for funds even more difficult, as Willis Shapley described so vividly at the October Centennial meeting. And Shapley had not yet got into the controversial politics of the late $30^{\prime} \mathrm{s}$ and $40^{\prime} \mathrm{s}$ which would be a drain on his energy and capabilities, with his ever strong desire to help humanity, individually and collectively.

When he came to Harvard he gave up access to the largest telescopes in the world at Mount Wilson, but gained access to smaller scale photographs of the entire southern sky. These drew him increasingly into studies of the Magellanic Clouds and catalogues of galaxies. As Owen Gingerich (1985) has written in Harvard Magazine "at Harvard he never again made a first rate cosmological discovery, .... but few astronomers make even one breakthrough as brilliant as his." In one of his later flings of research he returned to his earlier field of binaries, 
the subject of his doctoral thesis at Princeton under Henry Norris Russel1 and presented in 1946 a paper on the W Ursae Majoris stars at the Centennial Symposia of the observatory. I asked my office mate at the David Dunlap Observatory, Dr. Slavek Rucinski who is an expert on these stars, how Shapley's paper then compares with present ideas. He gave me a splendid technical analysis of various points in the paper, which some of you might like to read. The general conclusion is that the situation with various types of variables has changed so markedly in the last forty years that a good comparison of Shapley's findings then with opinions on these stars now is not really valid. For example, $18 \mathrm{~W}$ Ursae Majoris systems brighter than tenth magnitude were known then; there are at least 43 now.

But Shapley was much more than a matter-of-fact scientist. I found him to be one of the most fascinating individuals I have ever met. He had an amazing breadth of knowledge and quickness of response. Probably his earlier newspaper work had given him clever manipulation of the English language, and his sense of humor was delightful.

Through all these years he had the help of another brilliant individual, his wife, Martha Betz Shapley who helped in many ways, with his research as well as heavy social duties, while she brought up her family of five children. The Observatory parties at the Shapley home were greatly enjoyed and widely known, perhaps culminating in the rehearsals and performance of Pinafore in 1930, in which I myself was pretty much in the part of producer because of my previous theatrical experience. Dr. Shapley had shown me the old manuscript of the Observatory Pinafore when it was found after being lost for many years, and he asked me if I thought we could put it on - and we did:

Dr. Shapley put considerable effort into standing behind various astronomical activities associated with the Observatory such as the Bond Club, the AAVSO (American Association of Variable Star Observers), and of course the weekly colloquia. In my first one of these I heard Miss Payne speak as I recall, "On the Lifetime of an Excited Hydrogen Atom". Atomic physics had been under way for only a few years, and it embarrasses me still that I thought she was trying to inject humor into her title for a technical subject of which I had considerable ignorance.

Dr. Shapley was active in drawing distinguished visitors to the Observatory. Willem Luyten had already joined the staff from the Netherlands when I arrived, and Boris Gerasimovic came from Pulkova, (and tragically disappeared after his return to Russia), and Ejnar Hertzsprung from Leiden.

Shapley also strongly supported the American Astronomical Society and it was at its winter meeting at Yale in 1927 that I became a member of it and also was drawn into the branch of globular clusters which I still pursue. At that meeting Dr. Jan Schilt of Columbia spoke up with determination to say that he was tired of people talking about the perfod-luminosity curve for Cepheids in globular clusters because 
there was too little material to be meaningful. This was, of course, intended as a direct hit at Shapley. After I returned to Harvard from the meeting, I began looking up all the relevant references, and rather reluctantly concluded that I agreed with Schilt. So I started the pursuit to find more long period Cepheids in globular clusters, and to do this properly I needed to make a card catalogue of all available data to date. And 59 years later I am still keeping this catalogue up to date as I work toward the publication, with my colleague Christine Clement, of the Fourth Catalogue of Variable Stars in Globular Clusters.

In my final months at HCO in the spring of 1930 the epochal paper by Robert J. Trumpler proving the absorption of light in space from measures of the diameters of open clusters appeared in Lick Observatory Bulletin vol. 14, 1930. This was a sharp rebuff to Shapley's ideas, and he felt it deeply. For more than a decade he had refused to give in to the idea of such absorption. This was mainly because of the blue stars in the most distant globular cluster then known, NGC 7006. How could light be absorbed if it were still blue at the end of such a great distance? He asked me to review Trumpler's paper for a colloquium, knowing, I think that my empathy for the situation would lead me to deal with it as unabrasively as possible.

In September, 1930 Frank Hogg and I were married, and after an academic year I spent at Mount Holyoke, where, besides teaching full time I finished my doctoral thesis, and Frank spent at Amherst in research, we left Massachusetts in the summer of 1931 for the Dominion Astrophysical Observatory at Victoria, British Columbia. Dr. Shapley reminded me that the mails were still running, and we kept in touch for the rest of his life. In 1935 Frank and I moved to the University of Toronto where Frank was the Director of the David Dunlap Observatory and Chairman of the Department of Astronomy at the time of his death on January 1, 1951. Dr. Shapley made several visits there, speaking and capturing his hearers with his charm, honored by the highest circles of the city and university, and given an honorary degree from the $U$ of $T$. When he came, my husband and $I$, junior astronomers at the time, traveled with the elite, such as Sir Robert and Lady Falconer (he was Past President of $U$ of $T$ ) and Mrs. Dunlap who gave the Observatory to the University. In a letter I wrote to my family I give a long description of his visit to speak to the Royal Canadian Institute on November 16, 1935.

Later in 1939 I was on the special train with him for the opening of the McDonald Observatory in Texas. We visited the Shapley's in Dublin, N.H. a number of times, as my Massachusetts home was only 40 or so miles away.

And in 1952, Dr. Shapley invited me to teach elementary astronomy at Harvard Summer Schoo1, with David Heeschen (later the Director of National Radio Astronomy Observatory) as my first-rate helper. Once again I had many hours to enjoy Shapley's remarkable qualities. 
Those of us who were there could never forget the Celebration of Dr. Shapley's 80th birthday Noyember 9, 1965, at the American Academy of Arts and Sciences, then located in Brookline. Many people commented that Shapley often tried to do things in a flamboyant and spectacular way, and he certainly succeeded that night. For it was the night of the major electrical black out all over the eastern coast of the United States and into Canada. The dinner was for formal dress. I had just checked into the Commander Hotel and was about to get my formal attire out of my suitcase when presto - total darkness descended. It did not take me many minutes to realize this was serious, as there were no lights anywhere. Eventually some feeble ones came on in the hotel corridors. To make a long story short, the drive from Cambridge over to Brookline was horrendous, with no traffic lights. But for those who did arrive, the dinner was carried out beautifully because the caterer had a gas-fired truck, and hundreds of candles were already decorating the dining room tables. And $\mathrm{Dr}$. Shapley was in excellent form.

In recognition of Shapley's 80th birthday, Peter van de Kamp arranged for a series of five papers to appear in the Publications of the Astronomical Society of the Pacific, vo1. 77, 1965. Since this is now two decades in the past, these papers may not be familiar to all who are attending this symposium.

Dr. van de Kamp wrote on "The Galactocentric Evolution, a Reminiscent Narrative". His opening paragraph assessed Shapley's contribution in vivid terms.

"The galactocentric viewpoint developed by Harlow Shapley in 1917 represents a step forward in astronomical thinking and perception analogous to the introduction of the heliocentric viewpoint by Nicolaus Copernicus in 1543. The galactocentric viewpoint is now completely accepted and so taken for granted that it may be difficult for the younger astronomers to comprehend that it involved the overcoming of established systems and prejudices, and that this giant step forward was due not only to a substantial amount of observational work but above all to the insight, intuition, and courage of one individual, Harlow Shapley."

Helen Sawyer Hogg in "Harlow Shapley and Globular Clusters" outlined his most important papers on globular clusters and called attention especially to Shapley's work on Cepheid variables. "It was Shapley who named the curve 'Luminosity-period curve of Cepheid variables' in his paper 'On the Determination of the Distances of Globular clusters' ."

Carl Schalen wrote on "On Some Problems in Interstellar Absorption" and discussed the reasons Shapley obtained negative results in his studies of this.

"When Shapley started his pioneer investigations on the distributions in space of the globular clusters there were, according to results of J.C. Kapteyn, P.J. van Rhijn and others some indications of a 
possible small increase with distance of the color indices of stars, i.e. of a selective absorption in space. If this were real, stars in very distant objects like the globular clusters ought to be considerably reddened by the interstellar absorption. When studying the color indices of stars in Messier 13 (in 1915) Shapley unexpectedly discovered a large number of blue and white stars: out of 495 stars with well-determined color indices, 86 were found to be of color class b, and 63 of class a; and he did not find any exceptionally red stars. Shapley concluded that in the direction of Messier 13 the interstellar absorption must be extremely small. But in Shapley's words, 'That light scattering is absent in this direction is no proof that it does not occur elsewhere especially in low galactic latitudes where stars and diffuse nebulosity are concentrated' . . In 1915-17, when Shapley made his famous studies of these clusters nothing was known about the distribution of interstellar matter in the Galaxy. R.J. Trumpler's investigation in 1930 and subsequent papers by $P$. van de Kamp and others showed that interstellar matter is concentrated in a relatively thin layer near the galactic plane. Therefore, even very distant objects in high galactic latitudes show a relatively small amount of absorption as the light path through the interstellar medium is short".

Bart J. Bok described "Shapley's Researches on the Magellanic Clouds". His article opened with the dramatic sentence "For thirty years, from 1922 to 1952, Harlow Shapley was 'Mr. Magellanic Clouds'." And declares that "Harlow Shapley was first and foremost the cosmographer of the Magellanic Clouds".

Bok also mentioned Shapley's importance in fostering Miss Cannon's classification work.

"Shapley was instrumental in promoting the work by Miss Cannon and Mrs. Mayall in the field of spectral classification. It was realized soon after the publication of the Henry Draper Catalogue that the overall spectral survey did not really reach as faint as it should in the region of the Magellanic Clouds. Three publications in the Henry Draper Extension Series contain very valuable basic material for spectral studies of the fainter stars in the Clouds".

Actually as an example of the great increase in material which the H.D. Extension provided, S.I. Bailey cited (op. cit. p.159) a field of about 80 square degrees in the star cloud in Cygnus where one plate had the spectra of 4490 stars, of which only 498 were in the Henry Draper Catalogue, and 3992 had been added by the Extension.

The final article by Hudson Hoagland, a biologist, "Harlow Shapley - Some Recollections" provided some personal glimpses, a summary of his life, and a fine description of his famous desk.

"Harlow Shapley has honorary degrees from seventeen institutions and he has been made a foreign honorary member of national academies of 
ten foreign countries. He has been awarded medals and prizes by the Vatican, India, Mexico, England, France, et al. The diversity of his interests is reflected by the fact that he is a trustee of the Massachusetts Institute of Technology, the Worcester Foundation for Experimental Biology, the Woods Hole Oceanographic Institution, and Science Service. He has been the president of eight national scientific organizations. These include the American Academy of Arts and Sciences, Science Clubs of America, the Society of the Sigma Xi, American Astronomical Society, and the American Association for the Advancement of Science.

"His famous desk at the Harvard Observatory was symbolic of his way of 1ife. It was a desk in the form of a great wheel mounted on a vertical axle - a kind of rotating galaxy for ideas. Near the hub of the wheel were radially arranged compartments, cubby holes, and drawers. The disk of the wheel extended beyond the radius of these containers gave sample writing space for any position of the wheel. Thus sitting in one place, by turning the wheel, Shapley could bring before him any one of his divergent fields of interest. This marvelous desk thus allowed him, from his chair, to marshall the contents of half a dozen desk and files on as many topics by merely a twist of the wrist".

This morning I have tried to give you a view of Shapley's era from my personal association with him, which extended over four and a half decades. It is for the third speaker, Owen Gingerich, to sweep with a wider brush in describing "Shapley's Impact". But I would not like to end my own talk without some other opinion. The late Bart Bok, in obituaries of Harlow Shapley in the November, 1972 issue of Sky and Telescope and the Quarterly Journal of the Royal Astronomical Society, vol. 15, 1974 has given splendid summaries of Shapley's life and works. In the latter publication he writes "We can feel proud that our generation of astronomers produced a man who did for our Milky Way system what Copernicus achieved for our Solar System". And "Shapley was a great humanitarian, whose love for people and whose desire to assist them knew no bounds."

And now I will show you a few slides from my own old photo albums to give you a glimpse into Shapley's era as I knew it. Dr. Karl Kamper of the University of Toronto has expertly transformed some of the brownish photographs into fresh looking, but still quaint pictures.

The more significant of the slides appear as figures in this paper. Attention was drawn to Cecilia Payne, Emma T.R. Williams, and Margaret Walton (Maya11), Figure 4; to Frank Hogg, Helen Sawyer, (Hogg), Henrietta Swope and Adelaide Ames. (Figure 6.) Adelaide Ames whose name is well known for the Shapley-Ames catalogue of galaxies died tragically by drowning in 1932, but Henrletta Swope continued for half a century her researches on variable stars. After leaving Harvard she was on the staff of the Hale Observatories and in addition was a major benefactor of the Carnegie Southern Observatory at Las Campanas, Chile. Dr. Dorrit Hoffleit kindly provided material for one slide. 
Some of my slides capture the gay spirit of the 1920's, before the great depression, before World War II, and before anyone had used the words "atomic bomb".

\section{REFERENCES}

Bailey, S. I. 1932 Harvard Observatory Monographs No. 4.

Gingerich, 0. 1985 Harvard Magazine, Nov. Dec.

Shapley, H. 1969 Through Rugged Ways to the Stars, Charles Scribner's Son's, New York.

Trumpler, R.J. 1930 Lick Obs. Bul1. 14, 154. 